\title{
Delayed release pancrelipase for treatment of pancreatic exocrine insufficiency associated with chronic pancreatitis
}

This article was published in the following Dove Press journal:

Therapeutics and Clinical Risk Management

2 July 2009

Number of times this article has been viewed

\section{Devi Mukkai Krishnamurty' \\ Atoosa Rabiee ${ }^{2}$ \\ Sanjay B Jagannath' \\ Dana K Andersen²}

Johns Hopkins University School of Medicine; 'Department of Medicine; ${ }^{2}$ Department of Surgery, Johns Hopkins Hospital, Baltimore, MD, USA; ${ }^{2}$ Johns Hopkins University School of Medicine, Johns Hopkins Bayview Medical Center, Baltimore, MD, USA
Correspondence: Dana Andersen Johns Hopkins University School of Medicine, Department of Surgery, Johns Hopkins Hospital, Baltimore, MD, USA $\mathrm{Tel}+\mid$ 4I0 550282 I

Email dander54@jhmi.edu

\begin{abstract}
Pancreatic enzyme supplements (PES) are used in chronic pancreatitis (CP) for correction of pancreatic exocrine insufficiency (PEI) as well as pain and malnutrition. The use of porcine pancreatic enzymes for the correction of exocrine insufficiency is governed by the pathophysiology of the disease as well as pharmacologic properties of PES. Variability in bioequivalence of PES has been noted on in vitro and in vivo testing and has been attributed to the differences in enteric coating and the degree of micro-encapsulation. As a step towards standardizing pancreatic enzyme preparations, the Food and Drug Administration now requires the manufacturers of PES to obtain approval of marketed formulations by April 2010. In patients with treatment failure, apart from evaluating drug and dietary interactions and compliance, physicians should keep in mind that patients may benefit from switching to a different formulation. The choice of PES (enteric coated versus non-enteric coated) and the need for acid suppression should be individualized. There is no current standard test for evaluating adequacy of therapy in $\mathrm{CP}$ patients and studies have shown that optimization of therapy based on symptoms may be inadequate. Goals of therapy based on overall patient presentation and specific laboratory tests rather than mere correction of steatorrhea are needed.
\end{abstract}

Keywords: pancreatic exocrine insufficiency, chronic pancreatitis, pancreatic enzyme supplement

Chronic pancreatitis (CP) is a progressive inflammatory condition of the pancreas that is characterized by abdominal pain (usually) and is often associated with exocrine and endocrine insufficiency. The initiation of pancreatic enzyme supplements (PES) is common in the management of $\mathrm{CP}$ and other conditions associated with pancreatic enzyme insufficiency (PEI), such as cystic fibrosis $(\mathrm{CF})$ or pancreatic surgery. Through this review we present the existing data and guidelines on the use of PES in CP. The initial portion of the article will address the physiologic effects of PES, followed by the physiochemical properties of these preparations and clinical recommendations regarding their use.

\section{Physiologic effects of pancreatic exocrine insufficiency}

\section{Fat malabsorption}

The progressive destruction of pancreatic acinar cells leads to PEI. The most common clinical manifestation of PEI is steatorrhea, defined as more than 7 grams of fecal fat per day while consuming a $100 \mathrm{~g}$ fat diet. ${ }^{1}$ Pancreatic fat malabsorption usually precedes malabsorption of other macronutrients in $\mathrm{CP}$, and is related to various factors. There is 
rapid degradation of pancreatic lipase due to the presence of pancreatic proteases and acid in the duodenum. ${ }^{2,3}$ In addition, in the acidic duodenal milieu, bile salt precipitation and subsequent adsorption to undigested food reduces the bile salt pool. ${ }^{4,5}$ And finally, CP patients are believed to have a defect in ileal mucosal absorption of bile salts, effectively reducing the availability of bile salts for enterohepatic circulation. ${ }^{6}$ A final factor contributing to pancreatic steatorrhea is the presence of neurohormonal disturbances resulting in gallbladder hypomotility and accelerated gastric and intestinal transit ${ }^{7-9}$ (see section on Motility).

Steatorrhea occurs in CP only after the pancreatic enzyme output has diminished by $90 \%$ of the normal output. ${ }^{10,11}$ The large reserve capacity of the pancreas, noted in these earlier studies, may be due to the non-pancreatic gastric and lingual lipases. ${ }^{12}$ These enzymes, which play an insignificant role in fat digestion in healthy individuals, can contribute significantly to the digestion of dietary triglycerides (up to $30 \%$ ) in patients with PEI.

Approximately $50 \%$ of CP patients experience steatorrhea within a median of 10-12 years after the onset of CP, but this may vary based on the etiology of $\mathrm{CP} .{ }^{13,14}$ Early studies classified CP into two broad types: alcoholic (ACP) or non-alcoholic (NACP) (which is further subdivided into early-onset and late-onset NACP) (see Figure 1). Early-onset NACP occurs in children and adolescents and is often characterized by pain, but with longer preservation of pancreatic function and later development of calcifications as compared to alcoholic CP and lateonset NACP. PEI is less common with NACP than ACP. ${ }^{14}$

Randomized placebo controlled trials have shown that treatment with PES improves steatorrhea, as measured by increased fat absorption, reduced fecal fat excretion, decreased stool weight and frequency, improved stool consistency and improved symptom scores. ${ }^{15-18}$ Other studies have demonstrated that patients receiving PES report weight gain and improved quality of life, and studies demonstrate decreased defecation rates, ${ }^{19}$ increased cholesterol absorption and improved enterohepatic cycling of bile salts..$^{5,20}$

\section{Pain}

The pain in CP is the most debilitating symptom of the disease and often leads to malnutrition, especially if the pain is related to meals. ACP and early-onset NACP are more commonly associated with pain as compared to late-onset NACP. ${ }^{14}$ The pathogenesis of pain is multi-factorial and believed to be a result of perineural inflammation, visceral hyperalgesia, and increased pancreatic ductal and parenchymal pressure. Complications such as stones, strictures, and pseudocysts may also contribute to pain in $\mathrm{CP}$.

Cholecystokinin (CCK) may play an important role in $\mathrm{CP}$ related pain. Normal physiology is such that $\mathrm{CCK}$ releasing peptide (CCKrp), which is produced in the duodenum, stimulates the release of CCK. In turn, CCKrp is degraded by pancreatic serine proteases. In CP patients with $\mathrm{PEI}$, lack of serine proteases leads to uninhibited production of $\mathrm{CCK}$, a potent stimulator of pancreatic enzymes. This is believed to result in increased pancreatic ductal and parenchymal pressure, and hence pain. Several animal ${ }^{21}$ and human ${ }^{22}$ studies have supported the presence of this regulatory pathway, while others have not. ${ }^{23,24}$ The potential pain benefit of PES in CP pain is based on restoring this negative feedback mechanism.

Randomized controlled trials have suggested that nonenteric coated PES reduce pain in $\mathrm{CP},{ }^{25,26}$ whereas enteric coated forms are less beneficial. ${ }^{27-29}$ A meta-analysis did not support the use of PES for the relief of pain in all patients. ${ }^{30}$

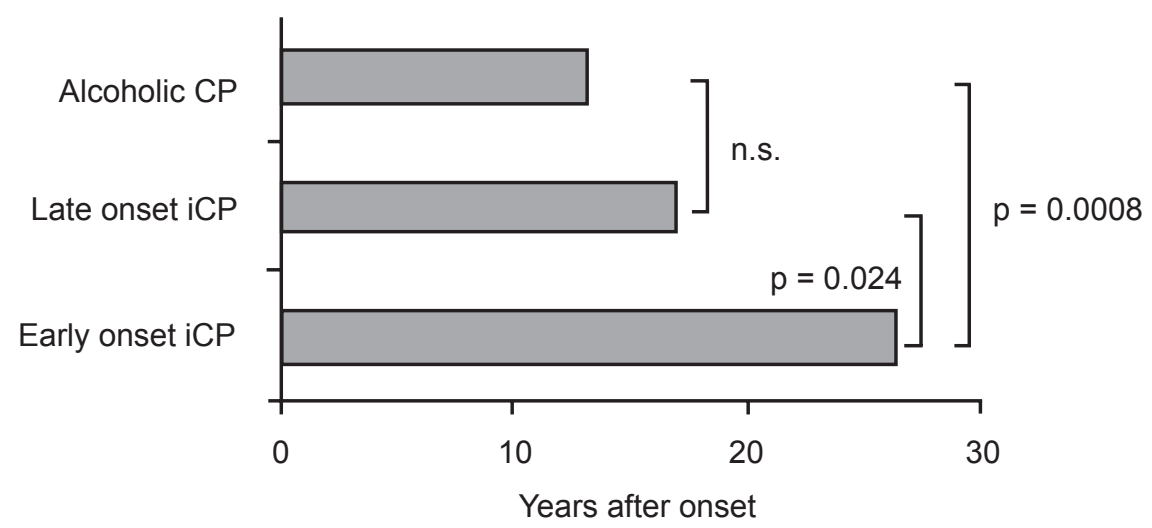

Figure I Onset of pancreatic exocrine insufficiency in patients with alcoholic and nonalcoholic etiologies. Reproduced with permission from Layer P, Keller J. 2003. Lipase supplementation therapy: standards, alternatives, and perspectives. Pancreas, 26: I-7. Copyright @ 2003 LippincottWilliams \&Wilkins.

Abbreviations: CP, chronic pancreatitis; iCP, idiopathic chronic pancreatitis. 
In the above studies, however, the patients with idiopathic $\mathrm{CP}$ and patients with less advanced disease ("small duct CP") achieved the greatest pain relief with PES. Enzyme preparations with high protease content may be more effective in reducing pain, while enzyme preparations with high lipase content are more effective in patients with steatorrhea. ${ }^{31}$ It is recommended that even though PES are limited in their effectiveness in pain relief, the non enteric coated forms are worth a trial in patients with less advanced disease, and further studies are needed to define whether certain subsets of patients with painful CP are more likely to respond to enzyme therapy.

\section{Motility disorders}

Motility disorders are common in patients with $\mathrm{CP}$, and are related to alterations in neurohormonal regulation. GI hormones such as CCK and pancreatic polypeptide (PP) are important in the regulation of GI motility. ${ }^{8,9}$ The endogenous release of these hormones is adversely affected by the presence of undigested food in the intestines. Abnormal CCK and PP levels have been observed in CP patients with PEI. In addition, the development of secondary (apancreatic) diabetes mellitus leading to autonomic neuropathy can further compromise GI motility. ${ }^{32}$

Abnormal motility patterns in $\mathrm{CP}$ patients include accelerated gastric emptying, ${ }^{7,33}$ altered post-prandial antroduodenal motility, ${ }^{9}$ and alterations in gallbladder motility (delayed gallbladder contraction and reduced gallbladder emptying) ${ }^{7,8}$ The severity of these abnormalities is often related to the degree of PEI and their presence often compounds the maldigestion and abdominal discomfort associated with $\mathrm{CP}$.

PES therapy is effective in normalizing the altered levels of GI hormones, ${ }^{7,34}$ and correcting accelerated gastric emptying $^{7,33}$ and abnormal antroduodenal motility. ${ }^{8,35}$ The normalization of such motility disorders may be attributed to improved lipid digestion and ileal braking induced by breakdown products such as oleic acids, triglycerides and short chain fatty acids. Improvement in gallbladder contraction with PES has been demonstrated in some studies ${ }^{36,37}$ but not in others.

\section{Malnutrition}

In CP patients with PEI, maldigestion of dietary macronutrients (fat, protein and carbohydrates) and poor oral intake lead to health problems associated with malnutrition. CP patients often suffer from malnutrition and have a low body mass index and asthenic body type.
Deficiencies in fat-soluble vitamins A, E and K may lead to symptoms such as impaired nighttime vision, cerebellar ataxia, and/or increased prothrombin time. ${ }^{38-40}$ When compared to healthy controls, CP patients have lower serum levels of vitamin $\mathrm{D}$, decreased bone mineral density and an increased incidence of osteoporosis. ${ }^{41-43}$ In addition, they may suffer from vitamin $\mathrm{B}_{12}$ deficiency due to both impaired release of $\mathrm{B}_{12}$ from complexes and bacterial overgrowth (a frequent finding in CP patients). ${ }^{44}$

Atherogenic alteration in serum lipoproteins(low levels of HDL-C and Apo-A) ${ }^{45}$ along with lifestyle factors such as smoking and alcohol may account for the increased prevalence of life-threatening cardiovascular lesions seen in CP patients. $^{46,47}$

Although elaborate trials are lacking, PES does help to ameliorate the malnutrition. A higher body weight and improved serum albumin levels have been demonstrated in $\mathrm{CP}$ patients who received PES. ${ }^{48}$ In malnourished CP patients with PEI, the optimization of PES therapy based on the results of C-13 Mixed Triglyceride breath test showed an improvement in fat digestion, body weight, serum levels of retinol binding protein (RBP) and the normalization of prealbumin after one year of optimized therapy. ${ }^{49}$ In addition, serum HDL levels have been shown to rise significantly, whereas levels of cholesterol or triglycerides in other lipoproteins remained unchanged $^{20}$ and this may have a cardioprotective effect. PES, however, is not sufficient for correcting fat soluble vitamin (A, D, E and $\mathrm{K}$ ) deficiencies or $\mathrm{B}_{12}$ deficiency, without simultaneous vitamin supplementation..$^{38,44}$

\section{Endocrine insufficiency}

Long-standing CP often culminates in brittle diabetes due to progressive destruction of the pancreas, and the clinical management of secondary (apancreatic) diabetes mellitus can be challenging. ${ }^{50}$ Carbohydrate malabsorption eases glucose intolerance, and the administration of PES may exacerbate diabetes. One randomized controlled trial with PES in patients with apancreatic diabetes revealed major difficulties with controlling blood sugars on changing from active enzyme replacement to placebo and vice versa, suggesting that enzyme adjustment should be carefully supervised in a hospital. ${ }^{16}$ In another randomized controlled trial of insulin-dependent diabetics with PEI, there were no significant differences in hemoglobin A1C, fasting glucose levels, or 2-hour postprandial glucose levels in patients receiving PES as compared to those not receiving $\mathrm{PES} .^{51} \mathrm{~A}$ reduction in mild and moderate hypoglycemia was observed in patients receiving PES and the authors concluded that PES therapy 
can be used safely in patients with diabetes mellitus and exocrine dysfunction.

\section{Effect on incretins}

Incretins (mainly GLP-1 (glucagon like peptide-1) and GIP (glucose-dependent insulinotropic polypeptide)) are insulinotropic intestinal peptide hormones released in response to simple carbohydrates and lipids, that cause an increase in the amount of insulin released from the beta cells in the pancreas. ${ }^{52}$ PES has been shown to restore the GIP response in CP patients. ${ }^{53}$ An increase in GLP-1 has also been described following PES. ${ }^{54}$ The increase in incretin levels was accompanied by an increase in plasma insulin and c-peptide levels, but without a significant lowering of plasma glucose levels (Figure 2). Knop et al concluded that the postprandial response of incretins is preserved in CP patients, and may be enhanced by the increased absorption of nutrients facilitated by pancreatic enzyme replacement.

\section{Pharmacology and clinical use of panceatic enzyme supplements PES preparations}

Porcine pancreatic enzymes are the current standard of treatment for PEI, and when protected from exposure to gastric acid, porcine lipase will not be degraded in the stomach. Pancreatin and pancrelipase are the two primary forms of porcine PES available, and pancrelipase has higher enzyme content (see below). Bovine enzymes are a potential alternative for individuals who refuse to consume porcine products for religious or other cultural reasons. ${ }^{55}$ The bovine preparations, however, contain approximately 75\% less lipase activity than the porcine and human preparations, and there is some concern about transmittable pathogens (Foot and mouth disease and Bovine spongiform encephalopathy) from bovine preparations.

Microbial preparations of pancreatic enzymes (lipase, protease, and amylase) also exist. ${ }^{56-59}$ Certain bacteria (eg, Burkholderia plantarii) and fungi (eg, Aspergillus niger, Rhizopus arrhizus) produce pancreatic enzymes with substantial lipolytic activity and greater resistance to gastric acid degradation. The microbial preparations do not require colipase for activation (see below for the importance of colipase). ${ }^{55}$ Of the microbial preparations fungal lipase is remarkably stable in the acidic gastric milieu, and is rapidly inactivated by bile acids and proteases whereas bacterial lipase has remarkable stability in both gastric and duodenal milieu, particularly in moderately acidic and neutral $\mathrm{pH}$.
In vitro studies have demonstrated bacterial lipase stability against proteases and bile salts and in vivo canine experiments show that bacterial lipase is more potent and efficacious than porcine PES. ${ }^{60-62}$ The efficacy of bacterial lipases is directly proportional to the fat content in the diet. The coefficient of fat absorption (explained below), which is about $70 \%$ with bacterial lipase and a low fat diet increases to about $90 \%$ with a high fat meal. ${ }^{58,59}$

A novel PES product, TheraCLEC-Total (TCT) containing a proprietary formulation of bacterial lipase and fungal protease and amylase, is being developed to aid the digestion of macronutrients. ${ }^{58,59} \mathrm{CF}$ patients with PEI who were treated with TCT experienced improvements in fat and nitrogen absorption, with the greatest improvement in patients with baseline fat absorption of less than $40 \%$. The most commonly reported adverse effects from TCT were mild gastrointestinal disorders and abnormal transaminases. Rarely, more serious pulmonary adverse effects and an episode of intestinal obstruction have also been reported. The mechanisms responsible for these adverse effects are not known.

Human lipase genes have been transfected and expressed using recombinant adenovirus carrier in vitro, ex vivo as well as in vivo. These genes have produced large amounts of human lipase, and in the future, ectopic expression of human lipase in the pancreatobiliary system may become an available treatment modality. ${ }^{63}$

\section{When to initiate PES}

PES should be initiated in patients suffering from CP and steatorrhea. In particular, the greatest benefit is seen in patients who experience weight loss and excrete greater than $15 \mathrm{~g}$ of fecal fat per day. ${ }^{64-66} \mathrm{~A}$ recent prospective trial was performed where the $\mathrm{C}-13$ medium chain triglyceride breath test was used to optimize PES therapy in CP patients who excrete less than $15 \mathrm{~g}$ of fecal fat per day. The results showed a significant improvement in the nutritional status of patients at one year follow up. ${ }^{66}$ Other indications to consider a trial of PES include patients with idiopathic or small duct CP who suffer from pain unresponsive to other simple treatment measures.

\section{When to administer PES}

It is widely accepted that PES should be given at the time of meals. This was demonstrated in 1977, by DiMagno et al who compared two PES administration schedules (hourly administration versus prandial administration) in patients with CP. Prandial administration of PES was more convenient and was as effective as hourly administration in abolishing steatorrhea 

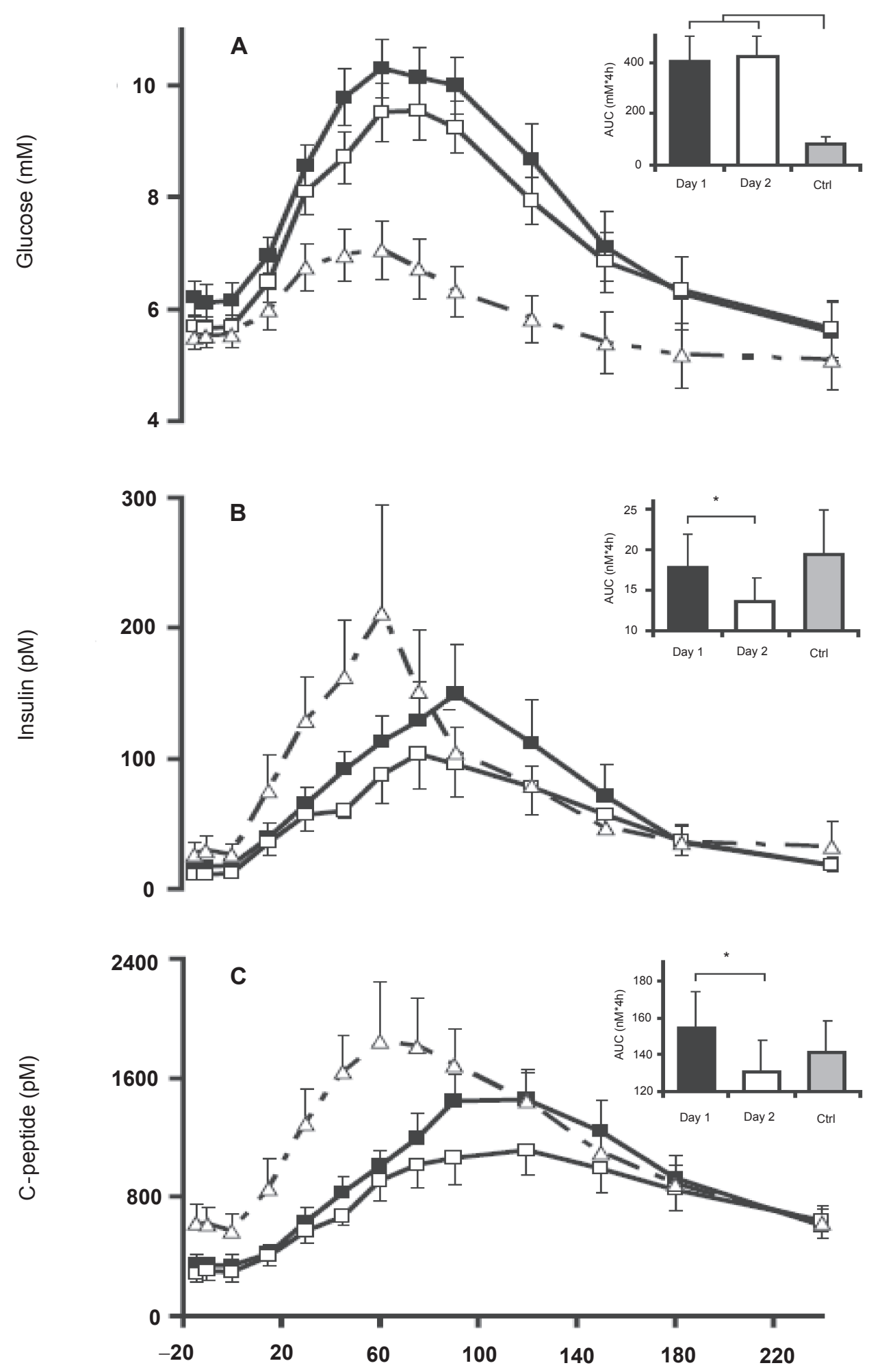

Time (minutes)

Figure 2 Plasma glucose (A), plasma insulin (B), and plasma C-peptide (C) concentrations in patients with chronic pancreatitis (CP) and pancreatic exocrine insufficiency (PEI) following ingestion of a liquid meal over $15 \mathrm{~min}(0-15 \mathrm{~min})$ with pancreatic enzyme substitution (PES; day I, $\mathbf{- 1})$ and without PES (day 2, $\square$ ). Punctuated curves ( $\Delta$ ) represent healthy control subjects (Ctrl) given an equal liquid meal without PES. Data are mean values \pm SE. Insets: AUC values. *Significant difference ( $P<0.05)$. Reproduced with permission from Knop FK, Vilsboll T, Larsen S, et al 2007. Increased postprandial responses of GLP-I and GIP in patients with chronic pancreatitis and steatorrhea following pancreatic enzyme substitution. Am J Physiol Endocrinol Metab, 292:E324-30. Copyright @ 2007 American Physiological Society. 
and perhaps more effective in abolishing azotorrhea. ${ }^{67}$ A recent prospective crossover randomized controlled trial compared three different prandial administration schedules of enteric coated mini-microspheres (less than $2 \mathrm{~mm}$ in diameter) in CP patients with PEI. The schedules were 4 capsules before meals, 4 capsules after meals and 4 capsules during meals ( 1 before-2 during-1 after meals). ${ }^{17}$ Fat digestion was optimal when the enzyme preparations were taken during or after meals and was better than the fat digestion observed when capsules were administered just before meals. Interestingly, there was no difference in patient's preference for the three dosing schedules in this study.

\section{Role of colipase}

Normal physiology mandates that colipase, a protein cofactor of lipase, is required in sufficient amounts in the small intestine to digest fat. ${ }^{68}$ Although devoid of enzymatic activity, colipase promotes pancreatic lipase activity by anchoring the enzyme on the surface of lipid droplets. Isolated colipase deficiency has been demonstrated as a sole cause of steatorrhea in patients with $\mathrm{PEI}^{69}$ and is a potential cause of treatment failure in patients receiving PES. All of the PES preparations commercially available in 1992 contained adequate quantities of colipase for effective lipid digestion. ${ }^{70}$

\section{Role of simultaneous acid supression}

The intraduodenal $\mathrm{pH}$ in untreated $\mathrm{CP}$ patients is acidic due to (1) increased production of gastric acid, ${ }^{71}$ (2) defective inhibition of gastric acid secretion, ${ }^{72}$ and (3) impaired secretion of bicarbonate into the duodenum from diseased pancreatic ductal epithelial cells. The resulting acidic intraduodenal milieu is responsible for the irreversible inactivation of pancreatic lipase, ${ }^{73,74}$ and the decreased functioning of bile salts. ${ }^{64}$ It has been demonstrated that patient response to conventional PES is enhanced if gastric acid secretion is suppressed. ${ }^{75}$

The need for additional therapy aimed at increasing intraduodenal $\mathrm{pH}$ to improve the response to PES is critical. This is most commonly accomplished using proton pump inhibitors (PPIs) and $\mathrm{H} 2$ receptor antagonists. When used concomitantly with 'conventional' PES preparations, acid suppression improves the concentration of lipase in the duodenum in patients with PEI. ${ }^{74}$ The use of acid suppression may appear unnecessary in patients receiving enteric coated forms of PES; however, some studies suggest that acid suppression is still required. ${ }^{76}$ It should be noted that the release of pancreatic enzymes from the enteric coating is dependent on the intraluminal $\mathrm{pH}$ (see section on enteric coated preparations). At the low intraduodenal $\mathrm{pH}$ levels seen in $\mathrm{CP}$, dissolution of the coating of these enzymes in the duodenum is, at best, partial with a more complete dissolution occurring distally in the small bowel as the $\mathrm{pH}$ rises. ${ }^{15}$ Patients who receive concomitant acid suppression with enteric coated PES have improved duodenal delivery of PES and more efficient utilization of the absorptive capacity of the intestines. ${ }^{77}$

Randomized controlled trials have demonstrated a significant improvement in fecal fat excretion with both enteric coated and non enteric coated PES and with simultaneous acid suppression (cimetidine or omeprazole) as compared to PES monotherapy. ${ }^{6,73,77,78}$ DiMagno $^{74}$ concluded that the addition of either $\mathrm{H} 2$ receptor antagonists or PPI to an adequate dose of PES will decrease fat malabsorption in most cases. One study suggested that if enteric coated mini-microsphere PES were administered with high dose PPI (omeprazole $60 \mathrm{mg}$ ), lower doses (10,000 lipase U tid) of the PES could achieve equal reduction in fecal fat excretion, improvement in abdominal symptom score and general well being when compared to standard (20,000 U tid) doses. ${ }^{79}$

It should be noted that impaired protein assimilation has been described in patients treated with omeprazole. ${ }^{80}$ The improvement in fat digestion seen with PES may be at the cost of decreased efficiency of protein digestion with the use of acid suppression. This was demonstrated in a prospective crossover study where the use of acid suppression with PES was associated with a marked decrease in the fat-protein content ratio in stool, ${ }^{81}$ suggesting an increase in fat absorption with a decrease in protein absorption. This concern should be kept in mind when prescribing acid suppression to patients with PEI.

\section{Enteric coated and micro-encapsulated pancreatic enzyme products}

The finding that acid degrades PES is well described. ${ }^{2}$ Along with the concomitant use of medication to suppress gastric acid, enteric coated PES preparations have been designed to resist degradation in the gastric lumen. The first generation of these preparations was the enteric coated tablet with a diameter of 11-20 mm, which did not show any additional benefit over conventional preparations. ${ }^{82,83}$ Scintigraphic and breath testing demonstrated poor gastric empyting of these preparations; a finding attributed to the large size of these early enteric coated preparations. ${ }^{84-86}$

The next generation of enteric coated preparations was coated microspheres. Each particle (over $2 \mathrm{~mm}$ in size) in the PES capsule was coated with its own acid resistant coating which was designed to stay intact at a $\mathrm{pH}$ of less than 4 , and immediately released between a $\mathrm{pH}$ of 5.0-5.5, 
thus theoretically improving duodenal delivery of the PES preparation.

No therapeutic benefit of these preparations was seen, due to failure of the larger microcapsules to exit the stomach with the meal they were intended to accompany, and hence the mini-microsphere (particle size 1-3 $\mathrm{mm}$ ) was designed. ${ }^{84}$ The small particle size ensured optimal mixing and synchronous delivery with food. Marked improvement in fat absorption was observed in a randomized controlled trial using mini-microsphere preparations; ${ }^{87}$ however, in a separate double blind multi-center cross-over study, there was no difference between the enteric coated microspheres and mini-microspheres in patients with PEI. ${ }^{88}$ Patients, though, preferred the mini-microsphere preparations over the microsphere preparations. Whether the use of these enteric coated mini-microsphere preparations adds any special advantage over the existing therapeutic modalities for the treatment of PEI with $\mathrm{CP}$ remains debatable.

The most recent innovation in the formulation of PES has been the development of enteric coated "buffered" microsphere preparations which have $1.5-2.5 \mathrm{mEq}$ of bicarbonate per capsule. Two randomized clinical trials have been conducted comparing these preparations to standard enteric coated microsphere preparations in CF patients with PEI, ${ }^{89,90}$ only one of which demonstrated reduction in steatorrhea with buffered PES. ${ }^{89}$

In vitro and in vivo studies have been performed on various commercially available PES preparations. ${ }^{91-93}$ Although most preparations had similar enzyme composition (ie, the quantity of amylase, lipase and protease), differences in dissolution properties have been observed. For example, even though each preparation tested contained the same amount of lipase, the amount of lipase released as a function of time and $\mathrm{pH}$ were found to be different, which was attributed to differences in the physiochemical properties of the enteric coating. The enteric coating may be detrimental to the release of pancreatic enzyme in vivo and may be associated with increased risk of complications (see below). Based on in vitro tests, Aloulou et al propose that the efficacy of enteric coated PES could be enhanced by adding unprotected enzymes. The efficacy of combining unprotected powder enzymes and enteric coated PES was not found to be superior to enteric coated microspheres alone in patients with CF. ${ }^{94}$ This combination therapy, however, has not been investigated in patients with $\mathrm{CP}$.

\section{Dose and formulation}

Since pancreatic steatorrhea does not occur until pancreatic lipase output is decreased by more than $90 \%,{ }^{10}$ the initial dose recommendations for PES is based on achieving $10 \%$ of normal postprandial lipolytic activity in the duodenal lumen. Based on these recommendations, the PES preparation must be able to produce $60 \mathrm{IU} / \mathrm{min}$ of lipase activity in postprandial chyme throughout the digestive period. A dose of 25-40,000 IU is thus recommended for the digestion of a regular meal ${ }^{55}$ which may be increased up to 2-3 fold in cases where it appears to lack a therapeutic effect (Figure 3).

A recent study has suggested that even higher than recommended doses of PES may be needed to digest fats, as the specific activity of human pancreatic lipase on dietary triglycerides was found to be three times less potent in vivo than seen previously under experimental conditions. ${ }^{95}$ Based on these findings, the authors suggest that higher doses of lipase may be required to completely normalize fat digestion. PES preparations containing higher lipase levels have proven to be more useful than standard preparations in the correction of PEI. ${ }^{96-98}$ Enteric coated microspheres with increased lipase content are currently available; however, higher doses of PES may cause serious side effects. Fibrosing colonopathy has been described in CF children taking PES, and hence doses greater than 75,000 IU of lipase per meal are not currently recommended (see below).

\section{Dietary interactions}

The ingestion of dietary fiber is associated with a small but significant increase in fecal fat excretion in CP patients with PEI. ${ }^{99}$ Recommending a high fiber diet or fiber supplements in CP patients may be problematic, despite the CP patient's tendency for constipation due to analgesic use. In addition, alcohol consumption has been noted to decrease lipase activity in CP patients by poorly characterized mechanisms. These levels recover in approximately 6 weeks in patients who abstain from alcohol. ${ }^{100}$ Therefore it is doubly important that all patients on PES abstain from alcohol.

Calcium and magnesium containing antacids are associated with the formation of calcium and magnesium soaps and the precipitation of glycine conjugated bile salts in the intestine. ${ }^{101}$ This leads to worsened steatorrhea in patients with PEI and thus such antacids are not recommended.

\section{Treatment failures, patient compliance and alternatives}

Lack of patient compliance may be a cause of treatment failure, and can be assessed clinically by measuring fecal chymotrypsin levels. ${ }^{55,102}$ In compliant patients not responding to PES, increasing the dose of PES by 2-3 fold along with distribution of calories across 5-6 smaller meals is 


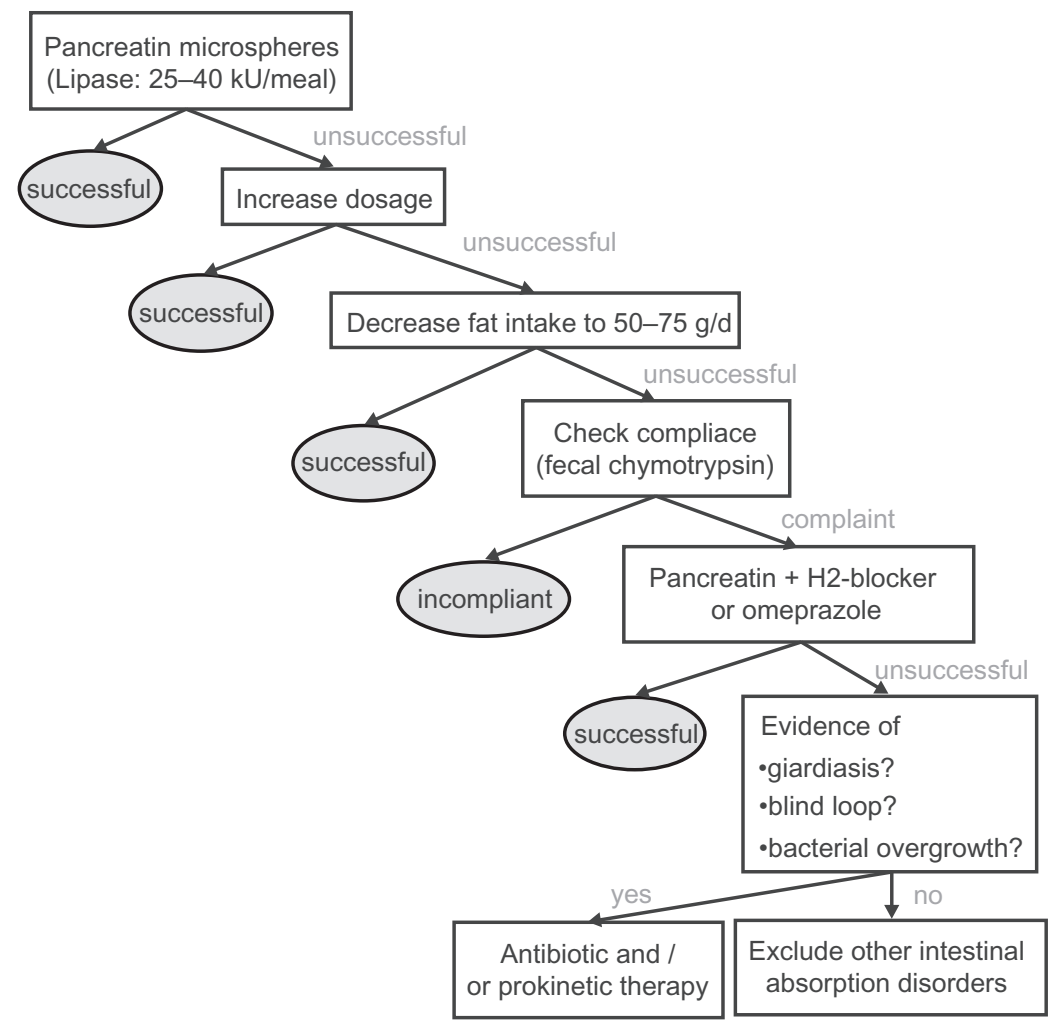

Figure 3 Current standard enzyme treatment of steatorrhea in chronic pancreatitis. Reproduced with permission from Layer P, Keller J. 2003. Lipase supplementation therapy: standards, alternatives, and perspectives. Pancreas, 26: I-7. Copyright (C) 2003 Lippincott Williams \& Wilkins.

recommended. PES preparations containing higher lipase levels have proven to be more useful for steatorrhea and may be tried in patients who do not respond to standard preparations. Medium chain triglycerides are not recommended as they do not offer any additional improvement in lipid digestion in patients receiving PES. ${ }^{103}$

Despite drug compliance and adequate dosing, treatment with PES alone in some patients with severe PEI will not lead to clinical improvement. Other factors may be responsible, either separately or in interplay with PEI. Such factors to consider include bacterial overgrowth of the small intestine, inadequate acid suppression, intestinal infections such as giardiasis, or other intestinal absorption disorders. Treatment failures can also occur following the substitution of a preferred brand with the generic formulation of PES. The lack of bioequivalence among different PES preparations is attributed to differences in the physicochemical properties of the enteric coating ${ }^{104,105}$ and has been confirmed by in vitro and in vivo studies (see below).

There is no standardized technique to assess treatment adequacy in patients receiving PES. Despite an adequate clinical response of malabsorption and steatorrhea in patients receiving PES, malnutrition may persist. Fecal fat estimation is considered the most reliable measure of fat malabsorption and various techniques ranging from clinical observation ${ }^{106}$ to the gold standard measures such as the van de Kramer method, ${ }^{107}$ the near infrared spectrometry ${ }^{108}$ and Nuclear magnetic Resonance (NMR) spectrometric fecal fat analysis ${ }^{109}$ have been described. Indices such as the coefficient of fat absorption ((ingested fat - excreted fat)/ingested fat *100), and daily fat excretion (excreted fat/ingested fat * 100) can be derived from dietary and fecal fat estimation. Various other clinical (Body weight, nutritional status, frequency of bowel movements, stool character, abdominal pain, global disease symptom score, quality of life score) as well as laboratory indicators (fecal elastase, fecal chymotrypsin, etc) may be used to test adequacy of PES in various studies. Of the laboratory tests, fecal elastase is a useful non-invasive test for detection of PEI, ${ }^{110-112}$ but its usefulness in evaluating treatment compliance with PES has not been described.

Another test that has been used in various studies in patients with PEI is the $\mathrm{C}-13$ mixed triglyceride (MTG) breath test. ${ }^{113}$ It is a highly sensitive, specific, accurate and simple non-invasive test of exocrine pancreatic function with excellent correlation between pancreatic lipase output in the duodenum and the 6-hour cumulative ${ }^{13} \mathrm{CO} 2$ excretion in breath. The $\mathrm{C}-13$ breath test has been used in trials as a measure of adequacy of PES therapy in asymptomatic CP 
patients and adjustment of PES based on C-13 MTG breath test has been associated with improved nutritional status. ${ }^{77}$ Thus, improvement in clinical symptoms alone may not accurately predict therapeutic adequacy of PES, and better indicators to insure therapeutic benefit with enzyme supplementation are needed.

\section{In vitro tests}

The United States Pharmacopoeia ${ }^{114}$ has specific guidelines for in vitro assays for enzyme activity as well as dissolution characteristics for PES. The USP guidelines specify that each mg of Pancreatin contains no less than 2 USP units of lipase activity and 25 USP units of amylase and protease activity and each mg of pancrelipase contains no less than 24 USP units of lipase activity and 100 USP units of amylase and protease activity. Each capsule of these preparations should contain between $90 \%$ and $165 \%$ of the labeled lipase and not less than $90 \%$ of labeled activities of amylase and lipase ${ }^{92}$ (Table 1). The enteric coating of these enzymes is designed such that it remains intact at a $\mathrm{pH}$ of less than 4.0 and should dissolve rapidly and completely once the threshold $\mathrm{pH}$ (between 5.0 and 5.5 as selected by the manufacturer) is reached.

In vitro and in vivo studies have been performed to evaluate the bioequivalence of PES using these recommendations. ${ }^{91-93}$ All PES products evaluated in these tests were within the USP requirements for levels of amylase, lipase and protease and most preparations had far greater enzyme activity than the lower limit required by the USP. These studies raise the interesting concept of "overfill" seen with PES preparations to allow for enzyme deterioration during storage, so as to prolong "shelf life". This difference in dissolution properties of the enteric coating (see below) influences the enzyme activity in vitro as observed in these studies, and may be responsible for the observed difference in in vivo potency of the PES preparations.

\section{Food and Drug Administration (FDA) regulations}

PES drug product marketing in the United States predates the 1938 passage of the Federal Food, Drug, and Cosmetic Act. These drugs are required on a lifelong basis in patients with PEI to prevent malnutrition and associated complications, and it may be necessary to substitute a preferred product with a different or generic brand in patients with PEI for a variety of reasons. Unfortunately, therapeutic failures (gastrointestinal symptoms and fat malabsorption) have been noted in patients with $\mathrm{CF}$ after pharmacists substituted a preferred brand of PES with generic pancrelipase, which rapidly resolved after initial therapy was reinstituted. ${ }^{105}$

FDA's review of data and information on pancreatic extract drug products ${ }^{115}$ found significant variations in bioavailability among the various dosage forms and among products from different manufacturers of the same dosage form. In the last two decades, the FDA has been making efforts to regulate these inadequacies. On April 28, 2004, the FDA announced that all manufacturers of PES are required to submit a new drug application (NDA) and obtain approval by April 28, 2008, to be able to market these drug products. The approval deadline has recently been deferred until April 28,2010 , if the manufacturers have investigational new drug (IND) applications on active status on or before April 28, 2008, and have submitted an NDA on or before April 28,2009 . With these new requirements, there was only one approved PES preparation. This product Cotazym ${ }^{\circledR}$ (Organon, NJ, USA) was given FDA approval in 1996 but was taken off the market in August 2001.

\section{Adverse effects}

Hyperuricemia and hyperuricosuria leading to dysuria and uric acid crystaluria have been described in CF patients receiving PES. ${ }^{116}$ Allergic reactions to the porcine proteins may also occur. ${ }^{117}$ A fibrosing colonopathy has been described in children with CF receiving doses of PES above 24,000 U of lipase $/ \mathrm{kg} /$ day. ${ }^{118}$ Recent studies have demonstrated that intake of high doses of methacrylic copolymer used as acid resistant coating in PES rather than the lipase itself may be the cause of fibrosing colonopathy. ${ }^{119-121}$ This condition has also been reported in patients who have never received PES, but rather a different drug coated with methacrylic copolymer. ${ }^{122}$ Pancreatin extracts are also prone to form insoluble complexes with folic acid, with the result that folic acid deficiency can develop in patients receiving PES. More commonly seen adverse effects include nausea and diarrhea. PES are defined as pregnancy category B drugs, as there is inconclusive evidence for its use in lactation. ${ }^{123}$

\section{Summary}

Patients suffering from CP should be evaluated for the presence of PEI. PES is effective in the correction of steatorrhea and may have a role in reducing pain, improving motility, and correcting malnutrition in these patients. The choice of PES (enteric coated versus non-coated, tablets versus mini-microspheres, etc) and the need for acid suppression should be individualized. There is no current standard test for evaluating adequacy of therapy in $\mathrm{CP}$ patients and studies 
Table I Commercially available pancreatic enzyme (pancrelipase) preparations (Reproduced with permission from Ferrone M, Raimondo M, Scolapio JS. 2007. Pancreatic enzyme pharmacotherapy. Pharmacotherapy, 27:910-20. Copyright (C) 2007 Pharmacotherapy Publications)

\begin{tabular}{|c|c|c|c|}
\hline \multirow[t]{2}{*}{ Produce (distributor) } & \multicolumn{2}{|c|}{ Enzyme Content/Unit Dose (USP units) } & \multirow[b]{2}{*}{ Protease } \\
\hline & Lipase & Amylase & \\
\hline \multicolumn{4}{|l|}{ Immediate-release formulations } \\
\hline Pancrelipase tablets (various manufacturers) & 8000 & 30,000 & 30,000 \\
\hline Panokase tablets (various manufacturers) & 8000 & 30,000 & 30,000 \\
\hline Plaretase 8000 tablets (Ethex, St. Louis, MO) & 8000 & 30,000 & 30,000 \\
\hline Viokase 8 tablets (Paddock Labs, Minneapolis, MN) & 8000 & 30,000 & 30,000 \\
\hline Viokase 16 tablets (Axcan Scandipharm, Birmingham, AL) & 16,000 & 60,000 & 60,000 \\
\hline Viokase powder (Axcan Scandipharm) & 16,800 & 70,000 & 70,000 \\
\hline \multicolumn{4}{|l|}{ Enteric-coated minimicrospheres } \\
\hline Creon 5 SR capsules (Solvay Pharmceuticals, Marietta, GA) & 5000 & 16,600 & 18,750 \\
\hline Creon IO SR capsules (Solvay Pharmceuticals) & 10,000 & 33,220 & 37,500 \\
\hline Creon 20 SR capsules (Solvay Pharmceuticals) & 20,000 & 66,400 & 75,000 \\
\hline \multicolumn{4}{|l|}{ Enteric-coated microspheres } \\
\hline $\begin{array}{l}\text { Lipram } 4500 \text { DR capsules (Global Pharmaceuticals, } \\
\text { Philadelphia, PA) }\end{array}$ & 4500 & 20,000 & 25,000 \\
\hline Pancrelipase capsules (various manufacturers) & 4500 & 20,000 & 25,000 \\
\hline Pangestyme EC capsules (Ethex) & 4500 & 20,000 & 25,000 \\
\hline Ultrase capsules (Axcan Scandipharm) & 4500 & 20,000 & 25,000 \\
\hline Ku-Zyme HP capsules (Schwarz Pharma, Milwaukee,WI) & 8000 & 30,000 & 30,000 \\
\hline Lipram-PNIO DR capsules (Global Pharmaceuticals) & 10,000 & 30,000 & 30,000 \\
\hline Lipram-CRIO DR capsules (Global Pharmaceuticals) & 10,000 & 33,200 & 37,500 \\
\hline Palcaps I0 DR capsules (Carlsbad Technology, Carlsbad, CA) & 10,000 & 33,200 & 37,500 \\
\hline Pangestyme CN-IO DR capsules (Ethex) & 10,000 & 33,200 & 37,500 \\
\hline Lipram-ULI2 DR capsules (Global Pharmaceuticals) & 12,000 & 39,000 & 39,000 \\
\hline Pangestyme ULI2 DR capsules (Ethex) & 12,000 & 39,000 & 39,000 \\
\hline Pancrelipase capsules (various manufacturers) & 16,000 & 48,000 & 48,000 \\
\hline Pangestyme MTI6 DR capsules (Ethex) & 16,000 & 48,000 & 48,000 \\
\hline Panocaps MT I6 DR capsules (Carlsbad Technology) & 16,000 & 48,000 & 48,000 \\
\hline Lipram-PNI6 DR capsules (Global Pharmaceuticals) & 16,000 & 48,000 & 48,000 \\
\hline Lipram-ULI8 DR capsules (Global Pharmaceuticals) & 18,000 & 58,500 & 58,500 \\
\hline Pangestyme ULI8 DR capsules (Ethex) & 18,000 & 58,500 & 58,500 \\
\hline Lipram-PN20 DR capsules (Global Pharmaceuticals) & 20,000 & 56,000 & 44,000 \\
\hline Panocaps MT 20 DR capsules (Carlsbad Technology) & 20,000 & 56,000 & 44,000 \\
\hline Lipram-UL20 DR capsules (Global Pharmaceuticals) & 20,000 & 65,000 & 65,000 \\
\hline Pangestyme UL20 DR capsules (Ethex) & 20,000 & 65,000 & 65,000 \\
\hline Lipram-CR20 DR capsules (Global Pharmaceuticals) & 20,000 & 66,400 & 75,000 \\
\hline Palcaps 20 DR capsules (Carlsbad Technology) & 20,000 & 66,400 & 75,000 \\
\hline Pangestyme CN-20 DR capsules (Ethex) & 20,000 & 66,400 & 75,000 \\
\hline \multicolumn{4}{|l|}{ Enteric-coated microspheres with bicarbonate buffer } \\
\hline Pancrecarb MS-4 DR capsules (Digestive Care, Bethlehem, PA) & 4000 & 25,000 & 25,000 \\
\hline Pancrecarb MS-8 DR capsules (Digestive Care) & 8000 & 40,000 & 45,000 \\
\hline Pancrecarb MS-16 DR capsules (Digestive Care) & 16,000 & 52,000 & 52,000 \\
\hline \multicolumn{4}{|l|}{ Enteric-coated microtablets } \\
\hline Pancrease MT4 capsules (McNeil, Raritan, NJ) & 4000 & 12,000 & 12,000 \\
\hline Pancrease MTIO capsules (McNeil) & 10,000 & 30,000 & 10,000 \\
\hline Ultrase MTI2 capsules (Axcan Scandipharm) & 12,000 & 39,000 & 39,000 \\
\hline
\end{tabular}


Table I (Contiuned)

\begin{tabular}{llll}
\hline Pancrease MT I6 capsules (McNeil) & 16,000 & 48,000 & 48,000 \\
Ultrase MT I8 capsules (Axcan Scandipharm) & 18,000 & 58,500 & 58,500 \\
Pancrease MT 20 capsules (McNeil) & 20,000 & 56,000 & 44,000 \\
Ultrase MT 20 capsules (Axcan Scandipharm) & 20,000 & 65,000 & 65,000 \\
\hline
\end{tabular}

$\mathrm{SR}$, sustained release; $\mathrm{DR}$, delayed release.

aUnit is $1 / 4$ teaspoonful $=0.7 \mathrm{~g}$.

have shown that optimization of therapy based on symptoms alone may be inadequate. Goals of therapy based on overall patient presentation and specific laboratory tests rather than mere correction of steatorrhea are needed. Improved nutritional status is seen in patients receiving pancreatic enzyme replacement therapy, and the use of PES along with other medical and surgical modalities of treatment will significantly improve quality of life of patients with PEI.

\section{Disclosures}

None of the authors have conflicts of interest to disclose.

\section{Abbreviations}

$\mathrm{CP}$, chronic pancreatitis; PEI, pancreatic exocrine insufficiency; PES, pancreatic enzyme supplements; CF, cystic fibrosis; PPI, proton pump inhibitors.

\section{References}

1. Roberts IM, Poturich C, Wald A. Utility of fecal fat concentrations as screening test in pancreatic insufficiency. Dig Dis Sci. 1986;31:1021-1024.

2. Layer P, Go VL, Dimagno EP. Fate of pancreatic enzymes during small intestinal aboral transit in humans. Am J Physiol. 1986;251: G475-G480.

3. Holtmann G, Kelly DG, Sternby B, et al. Survival of human pancreatic enzymes during small bowel transit: effect of nutrients, bile acids, and enzymes. Am J Physiol. 1997;273:G553-G558.

4. Regan PT, Malagelada JR, Dimagno EP, et al. Reduced intraluminal bile acid concentrations and fat maldigestion in pancreatic insufficiency: correction by treatment. Gastroenterology. 1979;77:285-289.

5. Dutta SK, Anand K, Gadacz TR. Bile salt malabsorption in pancreatic insufficiency secondary to alcoholic pancreatitis. Gastroenterology. 1986;91:1243-1249.

6. Bruno MJ, Rauws EA, Hoek FJ, et al. Comparative effects of adjuvant cimetidine and omeprazole during pancreatic enzyme replacement therapy. Dig Dis Sci. 1994;39:988-992.

7. Mizushima T, Ochi K, Ichimura M, et al. Pancreatic enzyme supplement improves dysmotility in chronic pancreatitis patients. J Gastroenterol Hepatol. 2004;19:1005-1009.

8. Vu MK, Vecht J, Eddes EH, et al. Antroduodenal motility in chronic pancreatitis: are abnormalities related to exocrine insufficiency? Am J Physiol Gastrointest Liver Physiol. 2000;278:G458-G466.

9. Gielkens HA, Eddes EH, Vecht J, et al. Gallbladder motility and cholecystokinin secretion in chronic pancreatitis: relationship with exocrine pancreatic function. J Hepatol. 1997;27:306-312.

10. Dimagno EP, Go VL, Summerskill WH. Relations between pancreatic enzyme ouputs and malabsorption in severe pancreatic insufficiency. N Engl J Med. 1973;288:813-815.

11. Lankisch PG, Lembcke B, Wemken G, et al. Functional reserve capacity of the exocrine pancreas. Digestion. 1986;35:175-181.
12. Carriere F, Grandval P, Gregory PC, et al. Does the pancreas really produce much more lipase than required for fat digestion? JOP. 2005a;6:206-215.

13. Ammann RW, Buehler H, Muench R, et al. Differences in the natural history of idiopathic (nonalcoholic) and alcoholic chronic pancreatitis. A comparative long-term study of 287 patients. Pancreas. 1987;2:368-377.

14. Layer P, Yamamoto H, Kalthoff L, et al. The different courses of early- and late-onset idiopathic and alcoholic chronic pancreatitis. Gastroenterology. 1994;107:1481-1487.

15. Guarner L, Rodriguez R, Guarner F, et al. Fate of oral enzymes in pancreatic insufficiency. Gut. 1993;34:708-712.

16. O'Keefe SJ, Cariem AK, Levy M. The exacerbation of pancreatic endocrine dysfunction by potent pancreatic exocrine supplements in patients with chronic pancreatitis. J Clin Gastroenterol. 2001;32:319-323.

17. Dominguez-Munoz JE, Iglesias-Garcia J, Iglesias-Rey M, et al. Effect of the administration schedule on the therapeutic efficacy of oral pancreatic enzyme supplements in patients with exocrine pancreatic insufficiency: a randomized, three-way crossover study. Aliment Pharmacol Ther. 2005;21:993-1000.

18. Safdi M, Bekal PK, Martin S, et al. The effects of oral pancreatic enzymes (Creon 10 capsule) on steatorrhea: a multicenter, placebocontrolled, parallel group trial in subjects with chronic pancreatitis. Pancreas. 2006;33:156-162.

19. Czakó L, Takács T, Hegyi P, et al. Quality of life assessment after pancreatic enzyme replacement therapy in chronic pancreatitis. Can J Gastroenterol. 2003;17:597-603.

20. Vuoristo M, Vaananen H, Miettinen TA. Cholesterol malabsorption in pancreatic insufficiency: effects of enzyme substitution. Gastroenterology. 1992;102:647-655.

21. Folsch UR, Cantor P, Wilms HM, et al. Role of cholecystokinin in the negative feedback control of pancreatic enzyme secretion in conscious rats. Gastroenterology. 1987;92:449-958.

22. Owyang C. Negative feedback control of exocrine pancreatic secretion: role of cholecystokinin and cholinergic pathway. J Nutr. 1994;124:1321S-1326S.

23. Bozkurt T, Adler G, Koop I, et al. Plasma CCK levels in patients with pancreatic insufficiency. Dig Dis Sci. 1988;33:276-281.

24. Jansen JB, Hopman WP, Lamers CB. Plasma cholecystokinin concentrations in patients with pancreatic insufficiency measured by sequence-specific radioimmunoassays. Dig Dis Sci. 1984;29:1109-1117.

25. Isaksson G, Ihse I. Pain reduction by an oral pancreatic enzyme preparation in chronic pancreatitis. Dig Dis Sci. 1983;28:97-102.

26. Slaff J, Jacobson D, Tillman CR, et al. Protease-specific suppression of pancreatic exocrine secretion. Gastroenterology. 1984;87:44-52.

27. Halgreen H, Pedersen NT, Worning H. Symptomatic effect of pancreatic enzyme therapy in patients with chronic pancreatitis. Scand $J$ Gastroenterol. 1986;21:104-108.

28. Malesci A, Gaia E, Fioretta A, et al. No effect of long-term treatment with pancreatic extract on recurrent abdominal pain in patients with chronic pancreatitis. Scand J Gastroenterol. 1995;30:392-398.

29. Mossner J. Palliation of pain in chronic pancreatitis. Use of enzymes. Surg Clin North Am. 1999;79:861-872, xi.

30. Brown A, Hughes M, Tenner S, et al. Does pancreatic enzyme supplementation reduce pain in patients with chronic pancreatitis: a metaanalysis. Am J Gastroenterol. 1997;92:2032-2035. 
31. Greenberger NJ. Enzymatic therapy in patients with chronic pancreatitis. Gastroenterol Clin North Am. 1999;28:687-693.

32. Rosa ESL, Troncon LE, Gallo L JR, et al. Factors associated with abnormal gastric emptying in alcohol-related chronic pancreatitis. J Clin Gastroenterol. 2007;41:306-311.

33. Long WB, Weiss JB. Rapid gastric emptying of fatty meals in pancreatic insufficiency. Gastroenterology. 1974;67:920-925.

34. Nustede R, Kohler H, FolschUR, et al. Plasma concentrations of neurotensin and CCK in patients with chronic pancreatitis with and without enzyme substitution. Pancreas. 1991;6:260-265.

35. Layer P, Von Der Ohe MR, Holst JJ, et al. Altered postprandial motility in chronic pancreatitis: role of malabsorption. Gastroenterology. 1997; 112:1624-1634.

36. Masclee AA, Jansen JB, Corstens FH, et al. Reversible gall bladder dysfunction in severe pancreatic insufficiency. Gut. 1989;30:866-872.

37. Glasbrenner B, Malfertheiner P, Pieramico O, et al. Gallbladder dynamics in chronic pancreatitis. Relationship to exocrine pancreatic function, CCK, and PP release. Dig Dis Sci. 1993;38:482-489.

38. Dutta SK, Bustin MP, Russell RM, et al. Deficiency of fat-soluble vitamins in treated patients with pancreatic insufficiency. Ann Intern Med. 1982;97:549-552.

39. Marotta F, Labadarios D, Frazer L, et al. Fat-soluble vitamin concentration in chronic alcohol-induced pancreatitis. Relationship with steatorrhea. Dig Dis Sci. 1994;39:993-998.

40. Nakamura T, Takebe K, Imamura K, et al. Fat-soluble vitamins in patients with chronic pancreatitis (pancreatic insufficiency). Acta Gastroenterol Belg. 1996;59:10-14.

41. Moran CE, Sosa EG, Martinez SM, et al. Bone mineral density in patients with pancreatic insufficiency and steatorrhea. Am J Gastroenterol. 1997;92:867-871.

42. Haaber AB, Rosenfalck AM, Hansen B, et al. Bone mineral metabolism, bone mineral density, and body composition in patients with chronic pancreatitis and pancreatic exocrine insufficiency. Int $J$ Pancreatol. 2000;27:21-27.

43. Mann ST, Stracke H, Lange U, et al. Alterations of bone mineral density and bone metabolism in patients with various grades of chronic pancreatitis. Metabolism. 2003;52:579-585.

44. Bang Jorgensen B, Thorsgaard Pedersen N, Worning H. Short report: lipid and vitamin B12 malassimilation in pancreatic insufficiency. Aliment Pharmacol Ther. 1991;5:207-210.

45. Montalto G, Soresi M, Carroccio A, et al. Lipoproteins and chronic pancreatitis. Pancreas. 1994;9:137-138.

46. Tuzhilin DA, Dreiling DA. Cardiovascular lesions in pancreatitis. Am J Gastroenterol. 1975;63:381-388.

47. Gullo L, Stella A, Labriola E, et al. Cardiovascular lesions in chronic pancreatitis: a prospective study. Dig Dis Sci. 1982;27:716-722.

48. Trolli PA, Conwell DL, Zuccaro G, JR, Pancreatic enzyme therapy and nutritional status of outpatients with chronic pancreatitis. Gastroenterol Nurs. 2001;24:84-87.

49. Dominguez-Munoz JE. Pancreatic enzyme therapy for pancreatic exocrine insufficiency. Curr Gastroenterol Rep. 2007;9:116-122.

50. Andersen DK. Mechanisms and emerging treatments of the metabolic complications of chronic pancreatitis. Pancreas. 2007;35:1-15.

51. Ewald N, Bretzel RG, Fantus IG, et al. Pancreatin therapy in patients with insulin-treated diabetes mellitus and exocrine pancreatic insufficiency according to low fecal elastase 1 concentrations. Results of a prospective multi-centre trial. Diabetes Metab Res Rev. 2007;23: 386-391.

52. Creutzfeldt W. The [pre-] history of the incretin concept. Regul Pept. 2005;128:87-91.

53. Ebert R, Creutzfeldt W. Reversal of impaired GIP and insulin secretion in patients with pancreatogenic steatorrhea following enzyme substitution. Diabetologia. 1980;19:198-204.

54. Knop FK, Vilsboll T, Larsen S, et al. Increased postprandial responses of GLP-1 and GIP in patients with chronic pancreatitis and steatorrhea following pancreatic enzyme substitution. Am J Physiol Endocrinol Metab. 2007;292:E324-E330.
55. Layer P, Keller J. Lipase supplementation therapy: standards, alternatives, and perspectives. Pancreas. 2003;26:1-7.

56. Moreau J, Bouisson M, Saint-Marc-Girardin MF, et al. [Comparison of fungal lipase and pancreatic lipase in exocrine pancreatic insufficiency in man. Study of their in vitro properties and intraduodenal bioavailability]. Gastroenterol Clin Biol. 1988;12:787-792.

57. Zentler-Munro PL, Assoufi BA, Balasubramanian K, et al. Therapeutic potential and clinical efficacy of acid-resistant fungal lipase in the treatment of pancreatic steatorrhoea due to cystic fibrosis. Pancreas. 1992;7:311-319.

58. Borowitz D, Goss CH, Limauro S, et al. Study of a novel pancreatic enzyme replacement therapy in pancreatic insufficient subjects with cystic fibrosis. J Pediatr. 2006a;149:658-662.

59. Borowitz D, Goss CH, Stevens C, et al. Safety and preliminary clinical activity of a novel pancreatic enzyme preparation in pancreatic insufficient cystic fibrosis patients. Pancreas. 2006b;32:258-263.

60. Raimondo M, Dimagno EP. Lipolytic activity of bacterial lipase survives better than that of porcine lipase in human gastric and duodenal content. Gastroenterology. 1994;107:231-235.

61. Suzuki A, Mizumoto A, Sarr MG, et al. Bacterial lipase and high-fat diets in canine exocrine pancreatic insufficiency: a new therapy of steatorrhea? Gastroenterology. 1997;112:2048-2055.

62. Suzuki A, Mizumoto A, Rerknimitr R, et al. Effect of bacterial or porcine lipase with low- or high-fat diets on nutrient absorption in pancreatic-insufficient dogs. Gastroenterology. 1999;116:431-437.

63. Kuhel DG, Zheng S, Tso P, et al. Adenovirus-mediated human pancreatic lipase gene transfer to rat bile: gene therapy of fat malabsorption. Am J Physiol Gastrointest Liver Physiol. 2000;279:G1031-G1036.

64. Bruno MJ, Haverkort EB, Tytgat GN, et al. Maldigestion associated with exocrine pancreatic insufficiency: implications of gastrointestinal physiology and properties of enzyme preparations for a cause-related and patient-tailored treatment. Am J Gastroenterol. 1995;90:1383-1393.

65. Layer P, Keller J, Lankisch PG. Pancreatic enzyme replacement therapy. Curr Gastroenterol Rep. 2001;3:101-108.

66. Dominguez-Munoz JE, Iglesias-Garcia J, Vilarino-Insua M, et al. 13Cmixed triglyceride breath test to assess oral enzyme substitution therapy in patients with chronic pancreatitis. Clin Gastroenterol Hepatol. 2007:5:484-488.

67. Dimagno EP, Malagelada JR, Go VL, et al. Fate of orally ingested enzymes in pancreatic insufficiency. Comparison of two dosage schedules. N Engl J Med. 1977;296:1318-1322.

68. Brockman HL. Kinetic behavior of the pancreatic lipase-colipase-lipid system. Biochimie. 2000;82:987-995.

69. Gaskin KJ, Durie PR, Lee L, et al. Colipase and lipase secretion in childhood-onset pancreatic insufficiency. Delineation of patients with steatorrhea secondary to relative colipase deficiency. Gastroenterology. 1984;86:1-7.

70. Erlanson-Albertsson C, Wisen O. Enzyme substitution in pancreatic disease: is colipase activity sufficient? Scand J Gastroenterol. 1992;27:108-110.

71. Gullo L. Gastric acid secretion in chronic pancreatitis. Hepatogastoenterology. 1983;30:60-62.

72. Saunders JH, Cargill JM, Wormsley KG. Gastric secretion of acid in patients with pancreatic disease. Digestion. 1978;17:365-369.

73. Regan PT, Malagelada JR, Dimagno EP, et al. Comparative effects of antacids, cimetidine and enteric coating on the therapeutic response to oral enzymes in severe pancreatic insufficiency. $N$ Engl $J$ Med. 1977;297:854-858.

74. Dimagno EP. Gastric acid suppression and treatment of severe exocrine pancreatic insufficiency. Best Pract Res Clin Gastroenterol. 2001;15:477-486.

75. Graham DY. Pancreatic enzyme replacement: the effect of antacids or cimetidine. Dig Dis Sci. 1982;27:485-490.

76. Francisco MP, Wagner MH, Sherman JM, et al. Ranitidine and omeprazole as adjuvant therapy to pancrelipase to improve fat absorption in patients with cystic fibrosis. J Pediatr Gastroenterol Nutr. 2002;35:79-83. 
77. Saunders JH, Drummond S, Wormsley KG. Inhibition of gastric secretion in treatment of pancreatic insufficiency. Br Med J. 1977;1:418-419.

78. Dominguez-Munoz JE, Iglesias-Garcia J, Iglesias-Rey M, et al. Optimising the therapy of exocrine pancreatic insufficiency by the association of a proton pump inhibitor to enteric coated pancreatic extracts. Gut. 2006;55:1056-1057.

79. Vecht J, Symersky T, Lamers CB, et al. Efficacy of lower than standard doses of pancreatic enzyme supplementation therapy during acid inhibition in patients with pancreatic exocrine insufficiency. $J$ Clin Gastroenterol. 2006;40:721-725.

80. Evenepoel P, Claus D, Geypens B, et al. Evidence for impaired assimilation and increased colonic fermentation of protein, related to gastric acid suppression therapy. Aliment Pharmacol Ther. 1998;12: 1011-1019.

81. Delhaye M, Meuris S, Gohimont AC, et al. Comparative evaluation of a high lipase pancreatic enzyme preparation and a standard pancreatic supplement for treating exocrine pancreatic insufficiency in chronic pancreatitis. Eur J Gastroenterol Hepatol. 1996;8:699-703.

82. Graham DY. Enzyme replacement therapy of exocrine pancreatic insufficiency in man. Relations between in vitro enzyme activities and in vivo potency in commercial pancreatic extracts. $N$ Engl J Med. 1977;296:1314-1317.

83. Dutta SK, Rubin J, Harvey J. Comparative evaluation of the therapeutic efficacy of a pH-sensitive enteric coated pancreatic enzyme preparation with conventional pancreatic enzyme therapy in the treatment of exocrine pancreatic insufficiency. Gastroenterology. 1983;84:476-482.

84. Meyer JH, Elashoff J, Porter-Fink V, et al. Human postprandial gastric emptying of 1-3-millimeter spheres. Gastroenterology. 1988;94: 1315-1325.

85. Meyer JH, Lake R. Mismatch of duodenal deliveries of dietary fat and pancreatin from enterically coated microspheres. Pancreas. 1997; 15:226-235.

86. Bruno MJ, Borm JJ, Hoek FJ, et al. Gastric transit and pharmacodynamics of a two-millimeter enteric-coated pancreatin microsphere preparation in patients with chronic pancreatitis. Dig Dis Sci. 1998;43:203-213.

87. Stern RC, Eisenberg JD, Wagener JS, et al. A comparison of the efficacy and tolerance of pancrelipase and placebo in the treatment of steatorrhea in cystic fibrosis patients with clinical exocrine pancreatic insufficiency. Am J Gastroenterol. 2000;95:1932-1938.

88. Halm U, Loser C, Lohr M, et al. A double-blind, randomized, multicentre, crossover study to prove equivalence of pancreatin minimicrospheres versus microspheres in exocrine pancreatic insufficiency. Aliment Pharmacol Ther. 1999;13:951-957.

89. Brady MS, Garson JL, Krug SK, et al. An enteric-coated highbuffered pancrelipase reduces steatorrhea in patients with cystic fibrosis: a prospective, randomized study. J Am Diet Assoc. 2006;106: 1181-1186.

90. Kalnins D, Ellis L, Corey M, et al. Enteric-coated pancreatic enzyme with bicarbonate is equal to standard enteric-coated enzyme in treating malabsorption in cystic fibrosis. $J$ Pediatr Gastroenterol Nutr. 2006;42:256-261.

91. Kraisinger M, Hochhaus G, Stecenko A, et al. Clinical pharmacology of pancreatic enzymes in patients with cystic fibrosis and in vitro performance of microencapsulated formulations. J Clin Pharmacol. 1994;34:158-166.

92. Case CL, Henniges F, Barkin JS. Enzyme content and acid stability of enteric-coated pancreatic enzyme products in vitro. Pancreas. 2005;30:180-183.

93. Aloulou A, Puccinelli D, Sarles J, et al. In vitro comparative study of three pancreatic enzyme preparations: dissolution profiles, active enzyme release and acid stability. Aliment Pharmacol Ther. 2008;27:283-292.

94. Kalnins D, Corey M, Ellis L, et al. Combining unprotected pancreatic enzymes with $\mathrm{pH}$-sensitive enteric-coated microspheres does not improve nutrient digestion in patients with cystic fibrosis. $J$ Pediatr. 2005;146:489-493.
95. Carriere F, Grandval P, Renou C, et al. Quantitative study of digestive enzyme secretion and gastrointestinal lipolysis in chronic pancreatitis. Clin Gastroenterol Hepatol. 2005b;3:28-38.

96. Gan KH, Heijerman HG, Geus WP, et al. Comparison of a high lipase pancreatic enzyme extract with a regular pancreatin preparation in adult cystic fibrosis patients. Aliment Pharmacol Ther. 1994;8:603-607.

97. Malesci A, Mariani A, Mezzi G, et al. New enteric-coated high-lipase pancreatic extract in the treatment of pancreatic steatorrhea. $J$ Clin Gastroenterol. 1994;18:32-35.

98. Gullo L. Medical treatment of chronic pancreatitis. Ann Ital Chir. 2000;71:33-37.

99. Roggin GM, Iber FL, Linscheer WG. Intraluminal fat digestion in the chronic alcoholic. Gut. 1972;13:107-111.

100. Dutta SK, Hlasko J. Dietary fiber in pancreatic disease: effect of high fiber diet on fat malabsorption in pancreatic insufficiency and in vitro study of the interaction of dietary fiber with pancreatic enzymes. Am J Clin Nutr. 1985;41:517-525.

101. Graham DY, Sackman JW. Mechanism of increase in steatorrhea with calcium and magnesium in exocrine pancreatic insufficiency: an animal model. Gastroenterology. 1982;83:638-644.

102. Lankisch PG. What to do when a patient with exocrine pancreatic insufficiency does not respond to pancreatic enzyme substitution, a practical guide. Digestion. 1999;60(Suppl 1):97-103.

103. Caliari S, Benini L, Sembenini C, et al. Medium-chain triglyceride absorption in patients with pancreatic insufficiency. Scand $J$ Gastroenterol. 1996;31:90-94.

104. Hendeles L, Dorf A, Stecenko A, et al. Treatment failure after substitution of generic pancrelipase capsules. Correlation with in vitro lipase activity. JAMA. 1990;263:2459-2461.

105. Hendeles L, Hochhaus G, Kazerounian S. Generic and alternative brand-name pharmaceutical equivalents: select with caution. $\mathrm{Am} \mathrm{J}$ Hosp Pharm. 1993;50:323-329.

106. Lankisch PG, Dröge M, Hofses S, et al. Steatorrhoea: you cannot trust your eyes when it comes to diagnosis. Lancet. 1996;347:1620-1621.

107. Van De Kamer JH, Ten Bokkel Huinink H, Weyers HA. Rapid method for the determination of fat in feces. J Biol Chem. 1949;177:347-355.

108. Benini L, Caliari S, Guidi GC, et al. Near infrared spectrometry for faecal fat measurement: comparison with conventional gravimetric and titrimetric methods. Gut. 1989;30:1344-1347.

109. Schneider MU, Demling L, Domschke S, et al. NMR spectrometric stool fat analysis - a new technique for quantifying steatorrhea and establishing the indication for enzyme replacement in chronic pancreatitis. Hepatogastroenterology. 1985;32:210-215.

110. Loser C, Mollgaard A, Folsch UR. Faecal elastase 1: a novel, highly sensitive, and specific tubeless pancreatic function test. Gut. 1996;39:580-586.

111. Sonwalkar SA, Holbrook IB, Phillips I, et al. A prospective, comparative study of the para-aminobenzoic acid test and faecal elastase 1 in the assessment of exocrine pancreatic function. Aliment Pharmacol Ther. 2003;17:467-471.

112. Naruse S, Ishiguro H, Ko SB, et al. Fecal pancreatic elastase: a reproducible marker for severe exocrine pancreatic insufficiency. J Gastroenterol. 2006;41:901-908.

113. Vantrappen GR, Rutgeerts PJ, Ghoos YF, et al. Mixed triglyceride breath test: a noninvasive test of pancreatic lipase activity in the duodenum. Gastroenterology. 1989;96:1126-1134.

114. USP. Pancrelipase: Official Monograph In: The United States Pharmacopeia, The National Formulary. The United States Pharmacoepia Convention. 17(ed.) Rockville, MD;1989.

115. CDER. Guidelines for Industry. Exocrine pancreatic Insufficiency Drug Products - Submitting NDAs. Center or Drug Evaluation and Research, Food and Drug Administration, US Department of Health and Human Services; 2006.

116. Stapleton FB, Kennedy J, Nousia-Arvanitakis S, et al. Hyperuricosuria due to high-dose pancreatic extract therapy in cystic fibrosis. $N$ Engl J Med. 1976;295:246-248.

117. Pitchumoni CS. Chronic pancreatitis: pathogenesis and management of pain. J Clin Gastroenterol. 1998;27:101-107. 
118. Fitzsimmons SC, Burkhart GA, Borowitz D, et al. High-dose pancreatic-enzyme supplements and fibrosing colonopathy in children with cystic fibrosis. N Engl J Med. 1997;336:1283-1289.

119. Van Velzen D, Ball LM, Dezfulian AR, et al. Comparative and experimental pathology of fibrosing colonopathy. Postgrad Med J. 1996;72(Suppl 2):S39-S48; discussion S49-S51.

120. Prescott P. Pancreatic enzymes and fibrosing colonopathy. Lancet. $1999 ; 354: 250$.
121. Prescott $P$, Bakowski MT. Pathogenesis of fibrosing colonopathy: the role of methacrylic acid copolymer. Pharmacoepidemiol Drug Saf. 1999;8:377-384.

122. Gaia E, Sambatoro A, De Giuli P, et al. Adult fibrosing colonopathy associated with mesalazine treatment. Am J Gastroenterol. 2001; 96:2508-2509.

123. Ferrone M, Raimondo M, Scolapio JS. Pancreatic enzyme pharmacotherapy. Pharmacotherapy. 2007;27:910-920.

\section{Publish your work in this journal}

Therapeutics and Clinical Risk Management is an international, peerreviewed journal of clinical therapeutics and risk management, focusing on concise rapid reporting of clinical studies in all therapeutic areas, outcomes, safety, and programs for the effective, safe, and sustained use of medicines. This journal is indexed on PubMed Central, CAS,
EMBase, Scopus and the Elsevier Bibliographic databases. The manuscript management system is completely online and includes a very quick and fair peer-review system, which is all easy to use. Visit http://www.dovepress.com/testimonials.php to read real quotes from published authors.

Submit your manuscript here: http://www.dovepress.com/therapeutics-and-clinical-risk-management-journal 